\title{
A New School in the Study of India?
}

\author{
Jakob De Roover
}

\begin{abstract}
:
By arguing that a new 'School' is crystallising in the study of India, Deborah Sutton (2018) has brought to the surface phenomena that are typical of any encounter between competing research traditions. Some difficulties of understanding are caused by conceptual change: in the dominant research tradition, 'Hinduism' and 'the caste system' refer to structures that exist in Indian society; in the research programme developed by Balagangadhara, these terms designate experiential entities embedded in a western cultural experience of India. This conceptual divide also extends to the empirical: because the study of caste and Hinduism is collapsing under the weight of accumulated anomalies, certain problems are crucial to the alternative theorising of the Ghent School, whereas they seem irrelevant to the dominant tradition. Sutton engages in the polemics characteristic of confrontations between competing research traditions. She distorts and domesticates unfamiliar ideas from this School by mapping them onto notions familiar to her. Consequently, she confuses Balagangadhara's hypotheses about colonial consciousness with hackneyed stories about 'Orientalism'. The article concludes with a puzzle: Why does Sutton recognise a group of researchers as a new School, while trying to dismiss them as 'acolytes' who reproduce the 'mantras' and 'dogmas' of an Indian thinker?
\end{abstract}

Keywords: caste; Hinduism; Ghent School; Balagangadhara; Indian culture; research traditions

\section{Introduction}

In a recent article published in Contemporary South Asia, Deborah Sutton (2018) announces the emergence of a new school in the study of India. She coins the moniker 'Ghent School' to refer to this 'group of scholars whose ideas rotate around the work of S. N. Balagangadhara', because the latter first began developing his research programme at Ghent University $(2018,1-2)$. Sutton intends to explore the 
characteristics of this School's work and, more particularly, its position on caste. The end result, however, is puzzling. Consider some of her statements:

This scholarship - characterised by circular reasoning, self-referencing and a poverty of rigour - has established a modest, if contentious and poorly reviewed, presence in academic spheres of dissemination. (Sutton 2018, 1)

Authors associated with the Ghent School repeat, ad nauseam, what most scholars of religion and history regard as axiomatic: that scholarly terms and categories must be subject to critical reflection and rigorous definition. ...[Beyond] nebulous evocations of a more authentic Hindu identity, the Ghent School offer no new scholarly insight or innovation. (Sutton 2018, 4; emphasis added)

In Sutton's eyes, the relevant authors just keep reproducing the 'simple, central dogma' that colonial consciousness informs all scholarly work on Indian culture and society. And this concept of colonial consciousness developed by Balagangadhara, she claims, is but 'a crude derivative of Said's thesis on Orientalism' (ibid., 1).

The incongruity between word and deed must be apparent to any reader. If the Ghent School's work is characterized by such elementary flaws and if its academic presence is both modest and undeserved, why does Sutton feel compelled to write a fourteen-page journal article about this School and organise conference panels and seminars dedicated to its work? If its members offer no new ideas or insights, but only repeat in a crude form what others have already written before them or what most 
scholars regard as axiomatic, why dedicate precious research time and energy to this endeavour? ${ }^{1}$

Perhaps the reason behind Sutton's efforts lies in the Ghent School's alleged 'appeal for a Hindu chauvinist politics', at which she repeatedly hints (ibid., 2). But this is unconvincing: if the School's scholarship is 'marginalised' and contributes no new insights, as she insists, it should pose no threat at all, since Hindu nationalists should then be able to borrow the same ideas in a more sophisticated form from other scholars. In fact, Sutton herself points out the implausibility of these insinuations. She attributes to the Ghent School the claim that 'Hinduism' is a 'western fantasy' and that this religion does not exist in Indian society (ibid., 3). Hindu nationalism, on the contrary, bases its very existence on the premise that Hinduism exists, which is precisely what is denied in the research programme developed by Balagangadhara. In Anthony Copley's words, cited by Sutton $(2018,8)$, "if there is no Hinduism, [the Hindutva project] loses its raison d'être." In that case, Hindu nationalism and the Ghent School's account of Indian culture must be incompatible with each other: either the latter account is true and then the Hindu nationalist story about Indian culture must be false, or the other way around, but both cannot be true at the same time.

Sutton is so keen on insinuating some kind of 'alignment' between Hindu nationalist politics and the Ghent School's work that she misses the consequences of

\footnotetext{
${ }^{1}$ For instance, Sutton organised a panel at the 2017 annual meeting of the British Association for South Asian Studies, titled 'Right-wing Postcolonialism', which was dedicated to Balagangadhara's work and the Ghent School. In May 2018, she led a seminar ('Scandal and Scholarship: The Politics of Post-colonialism and Caste') at the University of Southampton with the same focus. She also writes to journal editors to object to the fact that their journals have published work by Balagangadhara and his students (see Sutton 2018, 5).
} 
this incompatibility. Just consider the relation between Darwinism and creationism. Many Darwinists and creationists share certain views - say, that we should care for our environment or that water consists of two hydrogen atoms attached to an oxygen atom but this does not affect the incompatibility between their two conceptual frameworks. Similarly, merely pointing out that Hindu nationalists and Ghent School researchers agree on certain claims tells us nothing about the relation between their two frameworks. Both groups agree on a variety of things: for instance, that, for any right triangle, the square of the length of the hypotenuse is equal to the sum of the squares of the length of its two legs, or that combustion is a chemical process where a substance reacts with an oxidant (usually oxygen), or that India is a beautiful country which should urgently do something about its air pollution and waste management, etc. However, all such 'concurrences' do nothing to reduce the incompatibility between the frameworks of Hindu nationalism and the Ghent School: these remain irreconcilable. ${ }^{2}$

What then inspires Sutton's campaign? Surely, she must have fundamental concerns about the Ghent School and its work, considering her extended efforts to discredit it. Prima facie, however, the nature of these concerns remains unclear in her text. In this article, I aim to make sense of Sutton's response and show its significance to the study of India. To do so, I turn to a series of insights about the growth of knowledge, which have their origin in the history and philosophy of science.

\footnotetext{
${ }^{2}$ Sutton suggests that the Ghent School shows 'a sense of affront' that is also characteristic of Hindu nationalism. In reality, however, this School shares with many others the analysis that there is something cognitively wrong with the currently dominant descriptions of Indian culture. Such cognitive concerns are distinct from the 'siege mentality' or 'politics of grievance' about the 'defamation' of 'the Indian nation', to which Sutton $(2018,4-8)$ repeatedly refers.
} 
In the 1960s and 1970s, several thinkers discovered that science does not grow cumulatively by adding new discoveries and theories to an existing body of knowledge, but that its more fundamental achievements result from competition between larger units of scientific activity: traditions of research, connected to a community of researchers and committed to a conceptual framework and models of scientific practice. ${ }^{3}$ Along with this discovery came insights into the type of problems that emerge when a new research tradition develops and begins to compete with the dominant one. Researchers working in such competing theoretical frameworks face peculiar difficulties in communicating their ideas to each other - a phenomenon called 'incommensurability' in the philosophy of science (Oberheim and Hoyningen-Huene 2016; Kuhn [1962]2012).

Sutton's article, I will argue, indicates that such an encounter between two research traditions is currently taking place in the study of India. She does so by highlighting a set of problems in the work resulting from the research programme built by Balagangadhara and his research group. It is worth exploring Sutton's observations, for if she is correct in her assessment that a new school is crystallizing in the study of India, this would throw new light upon the state of this field of study.

\footnotetext{
${ }^{3}$ Thomas Kuhn ([1962]2012) famously introduced the notion of paradigm to refer to these larger units. Imre Lakatos (1978) theorised them as research programmes, while Larry Laudan (1977) viewed scientific progress in terms of competition between research traditions. This article will use 'research programme' and 'research tradition' largely interchangeably but avoid 'paradigm' as much as possible because of its polysemy (Masterman 1970). In later work, Kuhn (1977) coined 'disciplinary matrix' to refer to a scientific community's commitments to a set of theoretical claims, instruments and techniques, and metaphysical beliefs.
} 


\section{So-called Caste?}

One of the typical problems of the encounter between competing research traditions has its origins in conceptual change. Some old concepts continue to be used in the new framework, but they are used differently than before. Basic terms like 'mass', 'temperature', 'earth', 'religion', 'value', or 'mind' are embedded in clusters of interrelated terms whose meaning is determined by a larger theoretical framework. Consequently, semantic relations change subtly or more visibly from one framework to the other and sentences which make perfect sense in one framework fail to do so in the other (Oberheim and Hoyningen-Huene 2016; Feyerabend 1981).

Against this background, the title of Sutton's piece is telling: 'So called caste'. She attributes to the Ghent School 'a spate of recent scholarly and social media declarations that reject the existence of caste and, by extension, caste discrimination' (Sutton 2018, 1). Its researchers, she says, 'maintain the mantra that caste represents a projection of the European imagination and that the use of the term "caste" as descriptive of any reality in India is an expression of "colonial consciousness", (ibid., 4). Sutton's claims contain an implicit question: How could one ever argue that caste and caste discrimination do not exist, when it is obvious to any observer that there are many castes in India and that some discriminate against others?

To see how misleading the above question is, we need to discover its roots in the difficulties caused by conceptual change. Let me clarify. Europeans were neither hallucinating nor projecting their imagination when they saw religion and caste in India, argues Balagangadhara (2012, 51-5). Instead, they shared an ordered experience, which crystallised over centuries of interaction between Europeans and India and its inhabitants. Like 'Hinduism', the term 'caste system' refers to an experiential entity: an entity-in-experience or pattern that orders the western cultural experience of India. 
How could one speak of such a cultural experience of India, considering the internal diversity of the western world? Part of the answer is found in the historical process from which this experience emerged. Travelling on the Subcontinent, Europeans with different backgrounds and origins observed all kinds of events, practices, things, and beings. They described these phenomena in terms available to them: certain practices constituted 'worship'; some people were followers of a 'religion', others were its 'priests'; these 'religions' had 'gods' and 'temples'; the different social groups were so many 'tribes' and 'castes'; their interaction was regulated by 'laws', either 'religious' or 'civil'; etc.

Mutatis mutandis, and allowing for internal variation, a similar process occurred in various Western-European languages. This was not simply a process of naming phenomena encountered in an alien part of the world. These terms were interrelated in the natural language usage of Europeans and embedded in larger semantic schemes. Consequently, when travellers, missionaries and other authors named the people, practices, and objects they observed, they were describing these as elements related to each other in larger patterns.

As first-hand reports of India reached Europe, scholars selectively drew upon these reports and upon ideas familiar to them and their readers, to create more systematic patterns in the descriptions of India. Some reflections about the people and social life of India were filtered out; others provided the material for sections on India in encyclopaedic works. For instance, standard accounts divided the people of India into a set of religious communities and presented the 'Hindu' majority as a 'nation' divided into castes and tribes, but united around a religion which sanctioned this social division and ranking. Certain texts in Sanskrit came to be conceptualised as sacred texts of this religion or as law books that regulate the social life of the Hindus. Some practices were understood as expressions of doctrines about purity and pollution or karma and rebirth. 
Out of this process emerged a cultural experience of India: an ordered experience mirrored in a body of descriptions, which postulates the existence of certain entities in Indian society.

Naturally, this is not to say that all Europeans experienced Indian culture and society in exactly the same way. Still, there were recurring patterns that gave shape to this cultural experience. These crystallised around shared clusters of ideas and attitudes, many of which had resulted from the secularisation of Christianity. 'Secularisation', here, does not mean the withdrawal of religion from the public sphere, but refers to a process whereby Christian religion expands and gives shape to a Christian-secular world, including common ideas and terms shared by people living in this world (Balagangadhara 1994; De Roover 2015). In one sense, this is obvious: centuries of Christian expansion in Europe could not but shape the natural language use of its inhabitants and produce widely held clusters of ideas as to what human beings are like. When people raised in this cultural setting travel to another continent, they inevitably draw on concepts available to them (and their potential readers) to describe the people and practices they encounter there.

What then is wrong with the resulting descriptions of caste and religion? The short answer is that they conflate the structure of experience with that of the world. Many problems in human interaction are caused by our tendency to think that our own experience of some event coincides with what occurred in the world. This tendency is also visible in Europe's encounter with other cultures. In fact, it generates a core characteristic of the western cultural experience of India: the structures that order this experience have been postulated as though they are structures in Indian cultural and social life. Today, the two experiential entities called 'Hinduism' and 'the caste system' continue to be mistaken for (representations of) entities that exist in Indian society. 
This fragment already reveals some basic conceptual shifts in the research programme developed by Balagangadhara. The term 'caste system' refers to an experiential entity, which exists as a pattern in western cultural experience, but not as a structure in the social world of India. The consequences for the usage of the term 'caste' and cognates like 'caste discrimination' must be clear: these can no longer be treated as neutral observational terms that refer to a set of phenomena obviously present in Indian society. Rather, they are part of the theoretical language shared across a body of descriptions of India.

\section{Conflating Description and Phenomenon}

In the face of a new research programme, the dominant scientific or scholarly community often ignores the fact that it is working within a framework. Its way of seeing and conceptualising the world has become so natural and familiar that it is difficult to imagine there could be other ways. This conflation of description and phenomenon leads to resistance against alternate hypotheses and to attempts to ridicule new ideas.

In her analysis, Sutton brings this problem to the surface: the concept of a nonexistent caste system or a fictitious Hinduism appears mad to her, as it must to many others. What is happening here? Indeed, members of the Ghent School sometimes speak of 'so-called caste' or 'so-called Hinduism' to indicate that these are not neutral observational terms with clear referents. However, this does not amount to a negation of facts such as the following: there are groups in Indian society referred to as ' $j a t i s$ ' or 'zat'; members of such groups sometimes treat each other in inhumane ways; 'varnas' are mentioned in Sanskrit texts; many Indians perform rituals, go to temples, recite shlokas, and tell stories of the devas and devis. To suggest that 'the caste system' and 'Hinduism' do not exist, is not equivalent to denying these phenomena. The research by Balagangadhara and others indicates a different problem: namely, characterising such 
phenomena in terms of 'caste' and 'religion' does not produce theory-neutral facts or observations, but conceptualisations that appear evident to people working within one framework but not to those in another.

Consider an illustration from the study of religion. In the dominant research tradition, it is evident that Christians and Hindus both partake in religious worship. A man going to church and praying to Christ performs the same kind of action as a man going to a temple and performing puja in front of Krishna. In this framework, these are two acts of 'worship', one Christian and the other Hindu. However, in the Ghent School's research programme, such observations do not show that Christianity and the Hindu traditions are two instances of the same phenomenon (religion), which involves 'worship' of 'supernatural beings'. Rather, the dominant research tradition relies upon a descriptive framework that mistakenly conceptualizes these two acts as instances of the same kind. This can happen only because of the presence of certain background ideas (for instance, the belief that all cultures have some form of religion and, therefore, some type of worship), which render the apparent similarities between these acts significant and self-evident. In fact, Balagangadhara (1994) shows how these are not two acts of worship: one is worship; the other is ritual; and worship and ritual are two distinct types of action.

Proponents of the dominant research tradition may find this ludicrous and say: 'How can you not see the similarities between these acts of religious worship?' Again, this is a familiar problem: there is no neutral observational language shared across the two frameworks, so the observations made by the two research communities differ, because they are structured by incompatible conceptual schemes. Moreover, similarities and dissimilarities become apparent and significant only because of the background framework that gives shape to the selection and description of facts. 
Does all of this mean that terms like 'religion' and 'caste' (or 'the secular' for that matter) are redundant? Not at all. Consider again 'caste'. Today, this term is used differently by different authors. In its current usage, however, it cannot but presuppose the existence of the caste system, since it derives its meaning from the larger conceptual framework that postulates this social structure in India. Yet, Sutton $(2018,4)$ is wrong in suggesting the implication that the usage of the term 'caste' as 'descriptive of any reality in India' will always be flawed. Possibly, new and better theories will emerge in the future, which draw upon this term to conceptualise Indian society in very different ways. In that case, 'caste' would end up having a different meaning and reference, much like 'religion' and 'the secular' have a different reference and meaning in Balagangadhara's alternative theory of religion (1994).

This point is important because of a genuine concern held by some critics of the Ghent School's work. In response to the thesis that the caste system does not exist or that the conception of a 'caste system' fails to provide an adequate description of the social structures and institutions of India, these critics raise the following question: Does this claim not risk denying the social effects of caste, namely, the injustices and conflicts in Indian society that are visible in the interaction between people from different jatis - more specifically, between 'higher castes' and 'lower castes'? ${ }^{4}$

When researchers from the Ghent School argue that the caste system is an experiential entity rather than a social structure of Indian society, they are not denying the forms of conflict, harm, and injustice that occur in interactions between people from different jatis. In fact, they are concerned about the obstacles that stand in the way of addressing these societal problems of contemporary India. The dominant ideas about

\footnotetext{
${ }^{4}$ The author would like to thank one of the anonymous referees of an earlier draft of this article for raising this issue.
} 
caste, including the idea that there is a caste system, have prevented us from adequately conceptualising such instances of conflict and injustice. The conflation of conceptualisation and phenomenon plays a harmful role here: it generates a tendency to presuppose that the description of Indian society in terms of 'the caste system' offers the only way of characterising the conflicts and injustices that occur in contacts between people from different 'castes'.

Once we undo this conflation of description ('the caste system and its effects') and phenomenon (the patterns of interaction among different jatis in Indian society), new space is opened up for formulating questions. Take some events encountered in Indian society today. In Tamil Nadu, conflicts between Vanniyars (a group classified as Other Backward Class or OBC) and several groups classified as Scheduled Castes are on the rise; the OBC group is increasingly violent towards members of these Scheduled Castes. In Andhra Pradesh, a group of Brahmins shows disdain and revulsion towards a group of Madigas, one of the Scheduled Castes, and avoids contact with them. In Bangalore, a Madhwa Brahmin family cleans the main room of its home after a visit from a Sanketi Brahmin neighbour; the family does the same after a TV repairman, presumably of 'lower-caste' origin, has entered its house. In a small town in Karnataka, some Lingayats scold Vaishnava Brahmins and claim that they are dirty people whom one should avoid; they proudly recount how their ancestors refused to take water from these Brahmins' hands.

What do we learn by claiming that all of these events are manifestations of the caste system? In some cases, concerns about physical contact and purity seem to play an important role in social interactions. However, when one tries to map these patterns of interaction onto a hierarchical social structure, one is stumped: the same types of restrictions occur in interaction between social groups that are allegedly of similar status; a group that is supposedly 'higher-ranked' can also be at the receiving end of the 
restrictions; so-called 'high-caste' groups do not exhibit the same behaviour towards 'lower castes' across contexts and regions. In other cases, it is plausible that the conflicts result from the policies and politics of post-Independence India, which build on the dominant story about 'the caste system'. Some stances are typical of how highly educated and cultivated people behave towards those they consider uncouth and uneducated; other attitudes are driven by resentment related to the consequences of caste-based reservations. Naturally, social scientists should figure out the nature of these events in order to help tackle related societal problems and conflicts. However, by clubbing together a range of attitudes, conflicts, and ways of acting, and by describing all of these as instances of 'the caste system', our knowledge does not increase. On the contrary, this labelling creates an illusion of understanding and thus prevents us from developing new hypotheses about the growing tensions that are undermining the coexistence of communities in Indian society.

\section{Anomalies and Obscurities}

The encounter between competing research traditions generally entails a conflict of views as to what counts as good research. Their respective proponents disagree about the problems that a theory must address and about the standards for evaluating proposed solutions. Therefore, problems that appear trivial or irrelevant to those working in an established research tradition can become crucial to an alternative research programme, and the other way around (see Oberheim and Hoyningen-Huene 2016).

Some of Sutton's remarks about the Ghent School should be seen in this light. Its members regularly point to conceptual and empirical problems in the currently dominant accounts of caste and religion. Sutton dismisses this as a 'demand for empirical certainty', which 'is echoed when the authors bemoan the absence of stable, empirical information about caste' $(2018,7)$. Rather than demanding 'empirical 
certainty', however, the authors she refers to are highlighting specific anomalies in the accounts about religion and caste in India.

Some of these anomalies are old indeed. From the $19^{\text {th }}$ century onwards, many scholars have argued that Hinduism is an 'amorphous' entity, rather than a distinct and coherent religion, since it does not know of any common doctrines, beliefs, or practices. They pointed out that most of the Hindus, including their 'priesthood', did not even know the content of their own 'sacred texts'. Others discovered the lack of clarity as to what type of unit the term 'caste' refers to or they found no correlation between varna and jati and no credible way of arranging the jatis in Indian society into a hierarchy; they also pointed out that castes generally value themselves highly and show pride about their jati (Blunt 1931, 8-9; Srinivas 1966, 9-15 and 1976, 169-70; Gupta 2000, 14; Gupta 2004; Guha 2013, 46). Why focus on these and similar problems?

To see the point, we need to understand another characteristic of research traditions. Each of these is surrounded by an ocean of anomalies: empirical observations and problems which violate the expectations induced by the framework but cannot be resolved within its confines. As research progresses, more and more of these anomalies come to the surface. Along the way, however, researchers active in the dominant research tradition aim to accommodate and neutralise the anomalies by modifying some of this tradition's ideas and making ad hoc adjustments to its conceptual framework.

This partially accounts for what has happened in the study of India. The accumulation of anomalies inspires scholars to develop new claims about caste and Hinduism, which should neutralise the impact of these anomalies. They modify old ideas so that the core of the current theorising about Indian culture and society remains immune to refutation. For instance, instead of a distinct and coherent religion, Hinduism is now characterised as 'a set of several distinct religions', 'a family of culturally related traditions', a 'polythetic category' or a 'Venn-diagram' with an empty centre 
(Stietencron 1997, 6; Lipner 2010, 6-7; Flood 1996, 5-8; Doniger 2014, 3-4). The fourtiered caste hierarchy becomes the 'textual' or 'Brahmanical' version of caste - a 'social ideal rather than a social reality' - as against the complex 'on-the-ground' interaction of castes in society, which is nevertheless supposed to constitute the caste system (Gupta 2000, 2-3; Jamison and Brereton 2014, 57).

In order to make sense of this kind of process, Imre Lakatos (1978) suggested that a research programme consists of a hard core of theses, surrounded by a protective belt of auxiliary hypotheses that immunises it against refutation. In the face of anomalies, researchers are reluctant to give up the hard core and instead develop new ideas by adjusting the protective belt and thus neutralising the anomalies. Indeed, in the study of India, scholars have been adjusting and re-adjusting the protective belt for many decades. This results in increasingly complicated and indeterminate stories about Hindu religion and caste; thus, they either actively protect the hard core from refutation or leave it untouched. In the end, they retain its body of basic assumptions, including the belief that Hinduism and the caste system exist in India.

In contrast, what unites researchers related to the Ghent School is that they are struck by the accumulated heap of anomalies in the study of India: empirical observations that violate expectations induced by the dominant framework; conceptual obscurities and inconsistencies that cannot be addressed within its confines. In Lakatosian terms, these authors insist that the protective belt has exhausted its capacity to protect the hard core against anomalies. In Kuhnian terms, a phase of crisis has arrived, where the old paradigm is collapsing under the weight of accumulated anomalies.

As this framework is coming apart at its seams, its concepts are becoming increasingly obscure. Indirectly, Sutton $(2018,4)$ acknowledges this: 'Sociologists and anthropologists have developed reflexive understandings of caste as a living dynamic in 
Indian society, a property that responds to its definitions in bureaucratic and political realms and is also constructed by everyday relations of kinship, gender, employment, ritual or sociality'. Such a sentence alone suffices to show how vacuous the notion of caste has become: one can substitute 'identity', 'religion', 'sexuality'... for 'caste' here, without any loss (or gain) of meaning and plausibility. Today's discourse about the caste system is equally poor in terms of empirical content: it does not simply ignore the accumulation of anomalies but even takes recourse to manipulation of data (Jalki and Pathan 2017). Many of its 'facts' turn out to be of the same nature as the 'fact' that the Eskimos know dozens of words for snow: stories repeated so often that no one cares to check their origin and veracity (Pullum 1991). Under such conditions, the only way to make progress is to give up the hard core of assumptions about religion and caste in India. Once one does so, the roots of many anomalies become clear: they result from gradually discovering that entities embedded in western cultural experience do not correspond to the structures of Indian culture and society.

\section{Domesticating the Unknown}

Critics of a newly developing research programme often seek to discredit it by reformulating its theses in such a way that they sound absurd and ridiculous or can be collapsed into familiar but suspect approaches. Such devices for distorting the views of one's opponents have always been common to polemics between different scientific and philosophical schools of thought. To take a famous illustration, Bishop Wilberforce tried to ridicule Darwin's theory of evolution by asking Thomas Huxley whether it was through his grandfather or his grandmother that he claimed his descent from a monkey (Lucas 1979).

The typical polemics between rival research traditions account for another aspect of Sutton's article: she consistently cites half-sentences or seems to 'paraphrase' ideas from publications by the Ghent School. Yet, her re-formulations - and the 
inferences she draws from them - are far away from representing the original ideas. In fact, almost every other sentence in her text attributes claims and verbiage to this School which are alien to its work: 'the enduring dominance of western epistemologies', 'a perpetual cultural and epistemic attack on India', 'a more authentic version of a Hindu Indian society', 'Hindu selfhood has experienced a double violation', 'evocations of a more authentic Hindu identity', 'a conspiracy of defamation on a global scale', etc. (Sutton 2018, 3-4, 11). In short, Sutton's rhetoric suggests that Balagangadhara and his students seek to recover a more authentic version of Hindu society or Hindu identity and a violated Hindu selfhood from the distortion effected by the dominance of "western epistemologies' and 'conspiracies of defamation'.

These and similar phrases are not only foreign to, but also incompatible with, the theorising of the Ghent School. First of all, the theories developed by this School deny the very existence of Hinduism and Hindu identity; this implies that there can be no such thing as 'Hindu society', authentic or inauthentic, and 'Hindu selfhood', violated or not. Secondly, its research programme is not concerned with issues of 'authenticity' or 'inauthenticity' but with the cognitive adequacy or inadequacy of the currently dominant accounts about Indian culture and society. Going by all the available standards of theory formation, these accounts fail to pass muster.

Thirdly, Ghent School researchers have emphasised that this cognitive inadequacy cannot be attributed to a conspiracy of defamation or hostile intent on the part of western or western-educated authors. Even those who seek to glorify India, from the Romantic and New Age movements to Hindutva ideologues, commit the same type of cognitive mistakes and reproduce the same clusters of ideas in different guises.

Neither can the problems be ascribed to the dominance of 'western epistemologies' or some 'insider-outsider' conflict: traditional Indian gurus and Sanskrit pundits engage in similar conceptual distortions in their discourses about 'Hindu philosophy' and their 
commentaries on Indian texts. This poses a challenge for any hypothesis that seeks to explain and address these problems. Throughout the decades, across cultural backgrounds and ideological frameworks, authors of different stripes and colours have faced similar cognitive obstacles in making sense of Indian culture, its traditions, and its texts. What must these obstacles be like to allow for this?

In the context of this question, let us take a closer look at Sutton's claims about Balagangadhara's 'concept of colonial consciousness'. According to her, this is but 'a crude derivative of Said's thesis of Orientalism' and a 'simplified Orientalism redux' $(2018,1-3,11)$. In fact, the hypotheses about colonial consciousness are logically and conceptually independent of Edward Said's claims about Orientalism (see Balagangadhara 2012,95-120). Said indeed revealed a set of systematic patterns in western conceptions of 'the East', which had been reproduced as 'facts' about the people living there. However, he never took the step of dissecting 'Orientalist discourse' as a body of descriptions of western cultural experience, for then he would have discovered that these descriptions share the same cognitive constraints and limitations as contemporary theorising in the social sciences and humanities. That is, much like Orientalism, the conceptual apparatus of these 'sciences' tends to mistake a particular cultural experience for a universal human experience; as a consequence, many of the constraints within which it conceptualises human beings and their societies coincide with the basic structures that form this cultural experience.

This is but one dimension of colonial consciousness: clusters of ideas, which mirror structures in western cultural experience, are adopted as though they provide an adequate framework for describing social and cultural phenomena in different parts of the world. Such a hypothesis generates new research questions. For instance, what happens when people who do not share this cultural experience nevertheless attempt to adopt the resulting framework to think about their own culture and society? How would 
they understand these clusters of ideas, given the fact that they have a different cultural experience structured by other conceptions as to what human beings and societies are like? Drawing upon Foucault's notion of 'discourse' and Gramsci's 'hegemony' or talking about 'the modern Orient' participating 'in its own Orientalising', as Said (1978) did, could never provide the theoretical apparatus required to grasp this phenomenon and its consequences.

Why does Sutton $(2018,3-4)$ confuse between such ideas? Why does she attribute to the Ghent School a long list of claims, which are nowhere to be found in its works? Apart from polemical purposes, at least part of this process of distortion is cognitive in nature. When Sutton reads sentences from these works, she is compelled to try and fit these into her own background framework and map them onto ideas familiar to her. But this is impossible, since the two sets of ideas are conceptually incompatible. As a consequence, she faces obstacles in grasping the coherence of textual passages that she reads. Rather than accessing the coherent whole of interrelated ideas expressed in the texts, she breaks up the textual fabric into half-sentences and pseudo-paraphrases, and thus digests it into units that end up representing her own ideas rather than those in the text.

\section{Competing Research Traditions}

The encounter between old and new research traditions has many more dimensions. Often the divide also extends to methods and standards for evaluating research. In her review of the Ghent School's writings about caste, Sutton $(2018,7)$ complains that they 'demand evidence of a non-contextual existence for a set of phenomena that all critical scholars have laboured to argue can only be properly understood in specific contexts'. Now, the claim that all phenomena exist in a specific context is a platitude (even a vacuum constitutes a context for the astronaut moving through it), so it is unclear why great labour would be required to argue this. 
Rather than demand the impossible, we need to appreciate a different concern: How can we study a phenomenon in its context, when we do not know how to recognise the phenomenon and discern its structure and characteristics? In that case, there would be no way of distinguishing between phenomenon and context, and between this and other phenomena; anything could then count as evidence of the alleged 'set of phenomena' that make up the caste system.

Consider an analogy: it is true that the current inflation in Venezuela can only be properly understood in the specific context of the Maduro government's policies and many other events. Even making this statement, however, presupposes answers to the following questions: How do we recognise the phenomenon of inflation (in Venezuela or elsewhere), what are its characteristics and consequences, and what counts as evidence of inflation? Now, imagine a social scientist telling you that these questions are misconceived, since one should not ask for 'empirical certainty' or 'stable, empirical information' about inflation. Instead, he insists, inflation should be studied as 'a living dynamic in Venezuelan society, a property that responds to its definitions in bureaucratic and political realms and is also constructed by everyday relations of employment, social status, gender, value, and modes of production'. This is the situation of the Ghent School: they raise questions about the structure and characteristics of the caste system and get answers as ill-conceived as the above.

Clearly, the standards held by members of competing research traditions can be very different. However, this does not entail the absence of reasonable grounds for preferring one research tradition above another. In one tradition, the number of references or displaying 'affinity' with the right authors is crucial to evaluating research results (Sutton 2018, 2-5); in another, consistency, coherence, and the capacity to predict new facts are essential. To a representative of one tradition, insisting on conceptual clarity and empirical evidence amounts to a misguided 'demand for 
empirical certainty' (ibid., 7); to the other, this is crucial for evaluating any set of hypotheses. To some, 'compelling' simplicity and 'crude' generalisations count against a theory (ibid., 2, 10); to others, they are virtues: 'A theory is the more impressive the greater the simplicity of its premises, the more different kinds of things it relates, and the more extended its area of applicability' (Einstein 1979, 31).

\section{Conclusion: An Emerging School?}

Perhaps the most intriguing aspect of Sutton's piece is her struggle to characterise the international research group coalescing around the programme developed by Balagangadhara. On the one hand, she feels compelled to coin the name 'Ghent School' and thus recognises this research group as a distinct school in the study of India. Now, under which conditions would one refer to a 'School' in the sciences or humanities? Minimally, there must be a relatively coherent body of thought, a cohesive group of researchers, and a growing set of research results which are gaining traction. Including the name of a city implies that it has functioned as a centre of intellectual activity for a group with significant impact upon some domain. That is why we speak of the

Frankfurter Schule, Wiener Kreis, and Kyoto School in philosophy or the Copenhagen School in quantum physics.

On the other hand, Sutton intends to deny academic respectability to the Ghent School. First, she tries to do so by claiming that its scholarship is poorly reviewed and lacks rigour. Yet, the articles and books produced by this School are published by highly regarded peer-review journals and publishers, so if they were poorly reviewed, this would be the case for humanities scholarship in general. Second, she insinuates some connection to Hindu nationalism, which we have already addressed. Third, suggestive language should get the job done: Sutton speaks of the 'charisma', 'acolytes', and 'followers' of Balagangadhara, of the School's 'self-marginalisation', 
'mantras' and 'central dogma', and of its 'polemical', 'hateful', and 'marginalised' scholarship.

What could explain this tension in Sutton's writing between recognising a group of researchers as a School and then trying to place them outside the realm of legitimate scholarship? More generally, how do we account for the peculiar combination of such attempts to dismiss this research group's work and the apparent urgency to publish journal articles and organise academic activities dedicated to 'the Ghent School'?

Again, the dynamics of interaction between competing research traditions can provide us with insights. As Ian Hacking (2012, xxii) explains, scientific communities cohere around a relative consensus and shared commitments: 'Accepted examples of scientific practice, including laws, theories, applications, experiment, and instrumentation, provide the models that create a coherent tradition and serve as the commitments which constitute a scientific community in the first place'. But what happens when a different community crystallises around a new research programme, which happens to be committed to other models of research practice? In such cases, the perception from within the dominant community is predictable: this new group is - or rather should be - outside the scientific community, since it does not live up to 'proper' standards of academic practice.

Sutton sees a new research community emerging in the study of India and hence refers to it as a 'School'. As is typically the case, this community does not abide by her models of 'scholarship'; it does not regard the same authors as authorities and has a different style of developing and articulating ideas; it does not show 'affinity' with the usual set of standpoints. Sutton also tends to confuse her circle of South Asia scholars for the academic community as a whole. All of this accounts for her perception that this School is 'marginalised': since they reject the models and assumptions to which she and her colleagues are committed, and do not don the straitjackets upon which scholarly 
reputations and careers depend in her field, they must be keen on 'self-marginalisation'. But why would people do this?

One typical ploy to make sense of the 'nonconformity' of an emerging school of thought is speaking in terms of the charisma and followers of a thinker. Still, something more insidious is going on here. The 'Ghent School' refers to an international research group consisting of individuals with all kinds of origins and backgrounds: Indians and Europeans, and even a Brit or two; Christians, Muslims, atheists, Jains, Sanketis, and people from a variety of other Indian traditions; members of all kinds of jatis, including Brahmins and Dalits. All of these have come together to work on a research programme developed by an Indian thinker and have published a series of books and articles that show the results. They are joined by hundreds of sympathisers in different parts of the world, who think that this research programme offers a promising alternative to the currently dominant frameworks.

To make sense of this phenomenon, why does Sutton turn to rhetoric about 'acolytes' and 'followers' who reproduce 'mantras' and 'dogmas' centred on the 'ideas' and 'charisma' of an Indian thinker and who place themselves outside the scope of scholarly 'orthodoxy'?

Note the sources of the terminology used by Sutton. As the Oxford English Dictionary evidences, all of these terms have their roots in a religious context. 'Acolytes' traditionally refers to persons who assist a priest and perform subordinate duties; the pejorative connotation of the term as subservient and mindless adherents draws from its religious origin. 'Followers' has a wider range of meanings; however, in the context of science and scholarship, the word also suggests the uncritical stance associated with adherents of a religious movement. The background of the terms 'mantra' and 'dogma' is obvious. The first term refers to a constantly and monotonously repeated phrase; this meaning has its origin in the English translation of this Sanskrit 
term as 'a word or phrase from a sacred text' repeated 'as a prayer or incantation'. The primary meaning of 'dogma' is 'a tenet or doctrine authoritatively laid down, esp. by a church or sect'. 'Charisma' originally refers to 'a free gift or favour specially vouchsafed by God' and 'a grace, a talent'; from this derives the secondary meaning of 'a gift or power of leadership or authority' and an 'aura' or 'capacity to inspire devotion or enthusiasm'. And 'orthodoxy' designates 'belief in or agreement with doctrines, opinions, or practices currently held to be right or correct, esp. in religious matters' ${ }^{5}$

The manner in which Sutton uses these terms in conjunction leaves no doubt as to the descriptive pattern she seeks to invoke: the Ghent School is a group of acolytes ('subservient and mindless followers') of a charismatic leader (to whom they attribute 'a god-gifted aura'), whose dogmas ('doctrines and tenets authoritatively laid down') they endlessly repeat as mantras ('prayers and incantations taken from texts regarded as sacred'), thus locating themselves beyond the orthodoxy ('in disagreement with the doctrines, opinions or practices currently held to be correct'). The origin of this descriptive pattern is well-known: it corresponds to how the Roman-Catholic Church characterised popular heresies during the Middle Ages (Moore 1995); it reproduces an age-old cliché of the western-Christian world, namely, the description of dissenting religious movements as 'cults' or 'sects'.

The insidious character of Sutton's rhetoric must be clear by now. Rather than doing the hard work of assessing the cognitive value of the hypotheses developed by the Ghent School, she resorts to language use aiming for cheap effect. She attempts to dismiss the School as a kind of sect located outside the realm of 'proper scholarship'. Apart from the polemics between competing research traditions, another dimension is

\footnotetext{
${ }^{5}$ See the online version of the Oxford English Dictionary for these meanings of the terms: http://www.oed.com
} 
involved in this case. Balagangadhara is a thinker of Indian origin, working on an alternative programme that challenges the conceptual foundations of several social science disciplines as they developed in the West. His students are a group of people with diverse cultural origins and backgrounds, who build on this programme because they think it generates knowledge about human beings and societies. They may be right or wrong; time will tell. Still, the route taken by Sutton to describe the Ghent School comes with a price: it assumes that it must be impossible for this Indian thinker to initiate such a new research programme, which appeals to diverse people for reasons of a cognitive nature. But why should this not be possible? Is it because fundamental theorising - the developing of new conceptual frameworks that challenge the foundations of the thinking that has come before - continues to be viewed as the privileged territory of western thinkers?

\section{References}

Balagangadhara, S. N. 1994. "The Heathen in His Blindness ...": Asia, the West, and the Dynamic of Religion. Leiden: Brill. . 2012. Reconceptualizing India Studies. New Delhi: Oxford University

Press.

Barber, Bernard. 1961. "Resistance by Scientists to Scientific Discovery," in Science 134: 596-602.

Blunt, Edward A. H. 1931. The Caste System of North India, with special reference to the United Provinces of Agra and Oudh. Madras: Oxford University Press.

De Roover, Jakob. 2015. Europe, India, and the Limits of Secularism. New Delhi: Oxford University Press.

Doniger, Wendy. 2014. On Hinduism. Oxford and New York: Oxford University Press. 
Einstein, Albert. 1979. Albert Einstein: Autobiographical Notes, translated by P. A.

Shilp. LaSalle and Chicago: Open Court.

Feyerabend, Paul. 1981. Realism, Rationalism \& Scientific Method: Philosophical

Papers, vol. 1. Cambridge: Cambridge University Press.

Flood, Gavin. 1996. An Introduction to Hinduism. Cambridge: Cambridge University Press.

Guha, Sumit. 2013. Beyond Caste: Identity and Power in South Asia, Past and Present.

Brill’s Indological Library, vol. 44. Leiden and Boston: Brill.

Gupta, Dipankar. 2000. Interrogating Caste: Understanding Hierarchy \& Difference in Indian Society. New Delhi: Penguin Books. . 2004. "Introduction: The certitudes of caste: When identity trumps hierarchy." In Caste in Question: Identity or Hierarchy?, edited by Dipankar Gupta. New Delhi: Sage.

Hacking, Ian. 2012. "Introductory Essay." In Thomas Kuhn, The Structure of Scientific Revolutions, $50^{\text {th }}$ anniversary edition. Chicago and London: The University of Chicago Press.

Jalki, Dunkin and Sufiya Pathan. 2017. "Are There Caste Atrocities in India? What the Data Can and Cannot Tell Us." In Western Foundations of the Caste System, edited by Martin Fárek et al. Cham: Palgrave Macmillan.

Jamison, Stephanie and Joel Brereton. 2014. The Rigveda: The Earliest Religious Poetry of India, vol. 1-3, transl. by Stephanie Jamison and Joel Brereton. Oxford and New York: Oxford University Press.

Kuhn, Thomas. [1962]2012. The Structure of Scientific Revolutions, 50 ${ }^{\text {th }}$ anniversary edition. Chicago and London: The University of Chicago Press. 
Kuhn, Thomas. 1977. "Second Thoughts on Paradigms.” In The Structure of Scientific Theories, edited by Frederick Suppe, 459-482. Urbana and Chicago: University of Illinois Press.

Lakatos, Imre. 1978. The Methodology of Scientific Research Programmes, Philosophical Papers, vol. 1. Cambridge: Cambridge University Press. Laudan, Larry. 1977. Progress and Its Problems: Towards a Theory of Scientific Growth. Berkeley and Los Angeles: University of California Press. Lipner, Julius. 2010. Hindus: Their Religious Beliefs and Practices. London and New York: Routledge.

Lucas, J.R. 1979. "Wilberforce and Huxley: A Legendary Encounter." The Historical Journal 22 (1): 313-330.

Masterman, Margaret. 1970. "The Nature of a Paradigm.” In Criticism and the Growth of Knowledge, edited by Imre Lakatos and Alan Musgrave, 59-89. Cambridge:

Cambridge University Press.

Moore, R. I. 1995. The Birth of Popular Heresy. Toronto: University of Toronto Press. Oberheim, Eric and Paul Hoyningen-Huene. 2016. "The Incommensurability of Scientific Theories' by Eric Oberheim and Paul Hoyningen-Huene.” In Stanford Encyclopedia of Philosophy (Winter 2016 Edition). URL = https://plato.stanford.edu/archives/win2016/entries/incommensurability/; accessed 29 July 2018.

Pullum, Geoffrey K. 1991. "The Great Eskimo Vocabulary Hoax.” Chapter 19 in The Great Eskimo Vocabulary Hoax and Other Irreverent Essays on the Study of Language. Chicago and London: The University of Chicago Press.

Said, Edward. 1978. Orientalism. London: Routledge \& Kegan Paul.

Srinivas, M. N. 1966. Social Change in Modern India. Hyderabad: Orient Longman. 
Srinivas, M. N. 1976. The Remembered Village. Berkeley and Los Angeles: University of California Press.

Sutton, Deborah R. 2018. "So called caste: S. N. Balagangadhara, the Ghent School and the Politics of grievance.” Contemporary South Asia 26 (3): 336-349.

Stietencron, Heinrich von. 1997. Hindu Religious Traditions and the Concept of

'Religion'. Amsterdam: Royal Netherlands Academy of Arts and Sciences. 